\title{
From Sugars to Nutritional Products - Active Ingredients
}

\author{
Werner Bonrath, Hans Kroon, Ulla Létinois, Maurus Marty*, Oliver May, Marc-André Müller, \\ Jan Schütz, and Bettina Wüstenberg
}

\begin{abstract}
A modern trend to carbon dioxide neutral production processes is based on renewable raw materials derived from sugars. Herein, an overview on modern approaches to fine chemicals for the nutritional industry is presented. In comparison to the traditional fossil-fuel-based processes the development of sustainable alternative transformations is necessary to enable the full potential of the new sustainable feedstocks.
\end{abstract}

Keywords: Fine chemicals · Nutraceuticals $\cdot$ Renewable feedstock $\cdot$ Vitamins

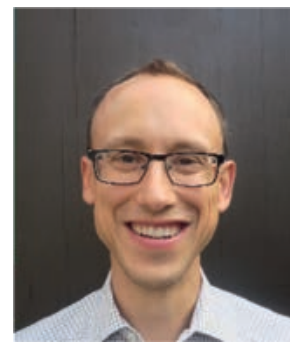

Jan Schütz, works as Senior Scientist at DSM Nutritional Products in Kaiseraugst, Switzerland. He is responsible for research and development in the organic synthesis of vitamins, nutraceuticals, and fragrance compounds. Special focus is on steroid syntheses regarding vitamin $\mathrm{D}_{3}$ and derivatives thereof and on heterogeneous catalysis in general, with focus on gas phase chemistry. Prior to joining DSM in 2005 he obtained his $\mathrm{PhD}$ in chemistry in the group of Prof. W.A. Herrmann at the Technical University of Munich, investigating the application of alternative $N$-heterocyclic carbene-metal complexes in homogeneous catalysis.

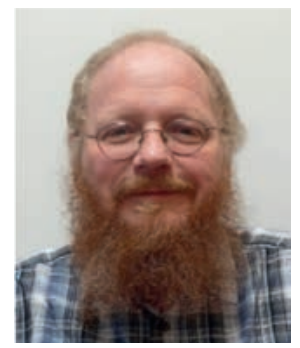

Werner Bonrath studied chemistry at the Universities of Bonn and Münster. He received his $\mathrm{PhD}$ at Max-Planck-Institute of Kohlenforschung and University of Bochum and his habilitation in Technical Chemistry at the University of Jena. He started his industrial career in 1989 and is now Senior Science Fellow for catalysis and process research at DSM.

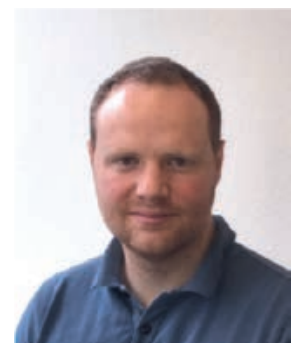

Marc Muiller received his $\mathrm{PhD}$ at the University of Basel in the group of Andreas Pfaltz followed by a post-doctoral stay at the Max-Planck-Institute für Kohlenforschung with Prof. Alois Fürstner. He started his industrial career at Dottikon ES where he was chemist in the high-pressure lab. Currently he is working at DSM in the field of process research.

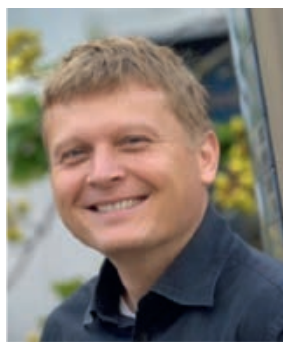

Oliver May studied Technical Biology and received his $\mathrm{PhD}$ from the University of Stuttgart (GER). Between 1998 and 2000 he did a Postdoc with Frances H. Arnold at Caltech (US). He started his industrial career in 2000 at Degussa and then joined DSM in 2006. After heading DSM's biocatalysis team he became R\&D Director of DSM Biobased Products and Services. In 2015 he joined DSM's Biotech Center in Delft (NL) as Senior Science Fellow, responsible for DSM's Biochemistry and Microbiology competence. In 2019 he joined DSM Nutritional Products in Kaiseraugst $(\mathrm{CH})$ where he is responsible for Biotechnology.

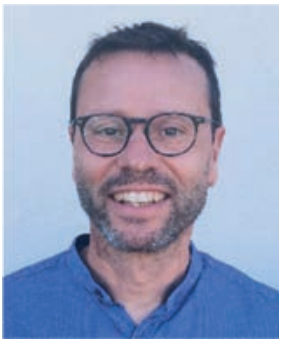

Maurus Marty studied organic chemistry in Fribourg and received his $\mathrm{PhD}$ from the University of Neuchâtel with Prof. Reinhard Neier. After an industrial PostDoc at Firmenich SA he did a second PostDoc with Prof. Jeremy Sanders at the University of Cambridge in Supramolecular Chemistry. He started his industrial career in 1997 in process research at Firmenich, where he worked as principal scientist until 2011. He then moved to Dottikon ES and 2013 to DSM in Sisseln as piloting manager.

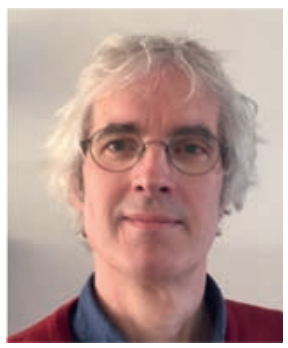

Hans Kroon works as a Senior Scientist in the DSM Applied Science Center on the sustainable of feed and materials and on process development of bio-based products like sugars, ethanol and levulinic acid from lignocellulosics with specific expertise on the initial processing steps of the feedstocks. He holds a MSc in Chemical Engineering from the University of Delft, and has broad experience in process development and design from lab to plant scale of various DSM processes. 


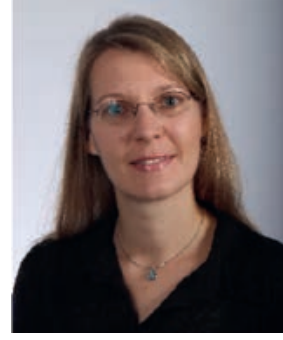

Bettina Wüstenberg studied chemistry at the Carl-von-Ossietzky University in Oldenburg and received her $\mathrm{PhD}$ from the University of Basel under the supervision of Prof. A. Pfaltz. For her postdoctoral studies she joined the group of Prof. N. Branda at Simon-Fraser University in Burnaby, Canada. Since 2005 she is working at DSM Nutritional Products in Kaiseraugst, Switzerland, in the Chemical Process Research Department, currently as EMEA Principal Scientist.

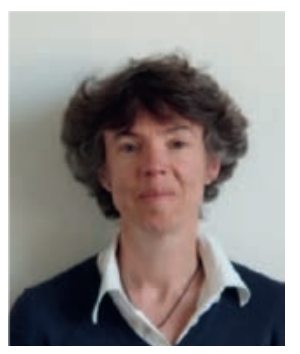

Ulla Létinois received her $\mathrm{PhD}$ in the frame of the European Doctoral College in Organic Chemistry from the University Louis Pasteur Strasbourg (F) and from the University of Leipzig (D) in 2003. After postdoctoral stays with Bernard Meunier in Toulouse (F) and Jean-Pierre Sauvage in Strasbourg $(\mathrm{F})$, she started working at DSM Nutritional Products in Kaiseraugst $(\mathrm{CH})$ in 2005. Since then her focus is on sustainable chemistry and Life Cycle Assessments of chemical and fermentative processes.

\section{Introduction}

Today, the majority of all fine chemicals and pharmaceuticals is produced from fossil resources such as coal and oil and to a much lesser extent from renewable sources such as sugars. During the last decades there has been a trend towards the increasing use of renewable resources, to replace existing production processes from fossil fuels or directly implement such processes in the production of new products. The replacement of existing processes from fossil resources to those from renewable materials faces various challenges such as chemical challenges, i.e. the high oxidation state of the renewable resources, biological ones such as highly varying percentages of cellulose, hemicellulose and lignocellulose.

In this article we highlight industrial production processes from renewable raw materials for fine chemicals, i.e. nutritional products and aroma ingredients, by using biological or chemical steps as well as combinations thereof to replace fossil feedstockbased processes.

\section{Fermentation}

Originally, the term 'fermentation' was used to describe anaerobic processes to convert sugars into alcohol. Today we use the term fermentation in a much broader sense as a process in which living cells are grown to produce products.

In addition, the replacement of many, tedious chemical manufacturing steps by microbial transformation has the potential for significant reduction in both the cost and the environmental footprint. The chemical industry is adopting these processes to shift from petroleum-based to bio-based feedstocks such as sugars.

One of the pioneering examples is the production of vitamin $\mathrm{C}$ which has an annual production volume of more than 100'000 tons per year. It is an example of a hybrid process, in which chemical and biological process steps are combined. Scheme 1 shows the Reichstein-Grüssner process, designed in 1933 where glucose is chemo-catalytically hydrogenated to sorbitol in a first step. The second step requires a highly regioselective oxidation which is difficult to achieve chemically but possible by microbes containing specific oxidoreductases which can oxidize alcohols into corresponding acids. The first microbe applied on industrial scale by Roche Vitamins (later acquired by DSM) was Gluconobacter oxydans which converted D-sorbitol into L-sorbose with high activity and selectivity. L-sorbose was then chemically protected using acetone and further oxidized into 2-keto-L-gulonic acid (2-KGA). A final lactonization step then yielded L-ascorbic acid (vitamin C). Today, industrial production processes use an additional biooxidation step with Ketogulonicigenium vulgare which can directly oxidize L-sorbose into 2-KGA without the need to isolate and protect the intermediate L-sorbose. ${ }^{[1]}$

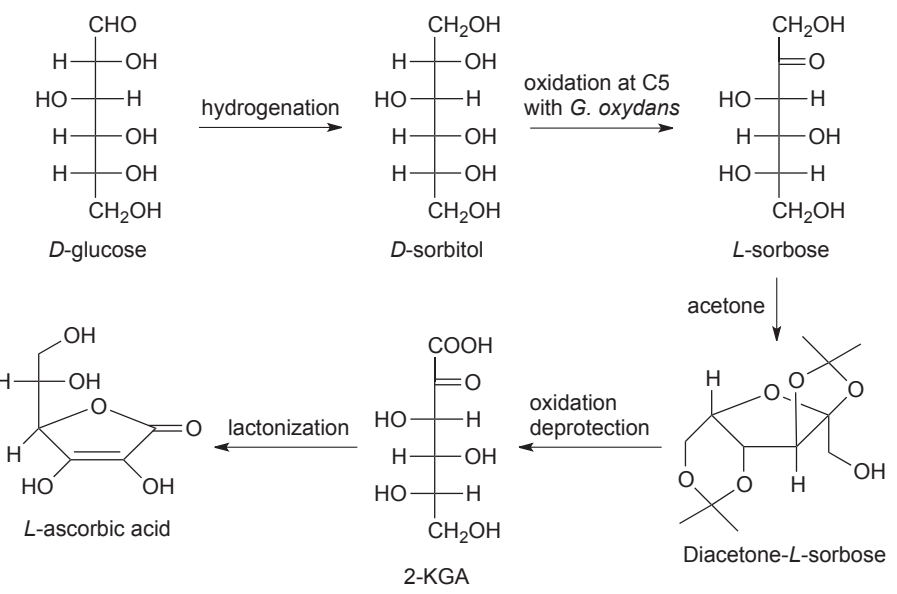

Scheme 1. Outline of the vitamin $\mathrm{C}$ synthesis according to the Reichstein-Grüssner process. ${ }^{[2]}$

Next to renewable feedstocks such as sugars, nature also provides us with a huge diversity of microorganisms, many of which are still to be discovered. It is estimated that Earth is home to as many as 1 trillion $\left(10^{12}\right)$ microbial species. ${ }^{[3]}$ To tap into this huge natural resource, the Nagoya Protocol defines access to natural resources under fair and equitable sharing of benefits, thereby contributing to the conservation and sustainable use of biodiversity. ${ }^{[4]}$ While this huge biodiversity allows us to tap into a huge number of natural compounds, modern biotechnology tools provide an additional dimension to even produce valuable compounds never invented by nature, or not available in a cost efficient and an environmentally friendly way to enable food, pharmaceutical, nutritional or other applications. For example, an inherent difficulty of many natural products is that they are present at such low concentrations that isolation of sufficient quantities of pure material for testing, let alone commercial production, is often very expensive, impossible, or environmentally destructive.

The advantage of applying modern biotechnology tools which enabled many applications since the mid 1980s will be demonstrated in the following based on DSM's developments for sugarbased production of vitamin $\mathrm{B}_{2}$ (Riboflavin).

Between the end of $1990 \mathrm{~s}$ and beginning of 2000 various chemical processes were replaced, applying recombinant microorganisms which delivered the products not only cost competitively and in the same or even higher purity but also with a significantly lower environmental footprint. Until the late 1990s vitamin $\mathrm{B}_{2}$ was chemically produced by Roche Vitamins (now DSM) from ribose, which was fermentatively obtained by converting glucose using Bacillus subtilis. Other fermentative processes were developed using the fungus Ashbya gosshypii. By introducing the full riboflavin biosynthesis pathway and regulating various other genes, the yield and productivity of the Bacillus subtilis strain was significantly improved, demonstrating the power of modern biotechnology tools. ${ }^{[5]}$ This optimized strain enabled a new generation riboflavin fermentation process for the cost competitive production of high quality vitamin $\mathrm{B}_{2}$ which is still operating today at DSM's facility in Grenzach (Germany). In addition to the improved economic performance and excellent product quality, a 
$36 \%$ reduction of waste and greenhouse gas emission as well as a $25 \%$ reduced energy consumption could be obtained compared to the previous combined fermentation and chemical process. ${ }^{[5]}$

\section{3. $\beta$-Farnesene and Derivatives}

The sesquiterpene artemisinin naturally occurs in the leaves and flowers of Artemisia annua and is applied in the treatment of Malaria tropica. Amyris, the University of California, Berkeley (UC Berkeley) and the company Sanofi collaborated on the first semisynthetic approach to artemisinin and artemisinin-based Combination Therapies (ACTs) (Scheme 2). ${ }^{[6,7]}$
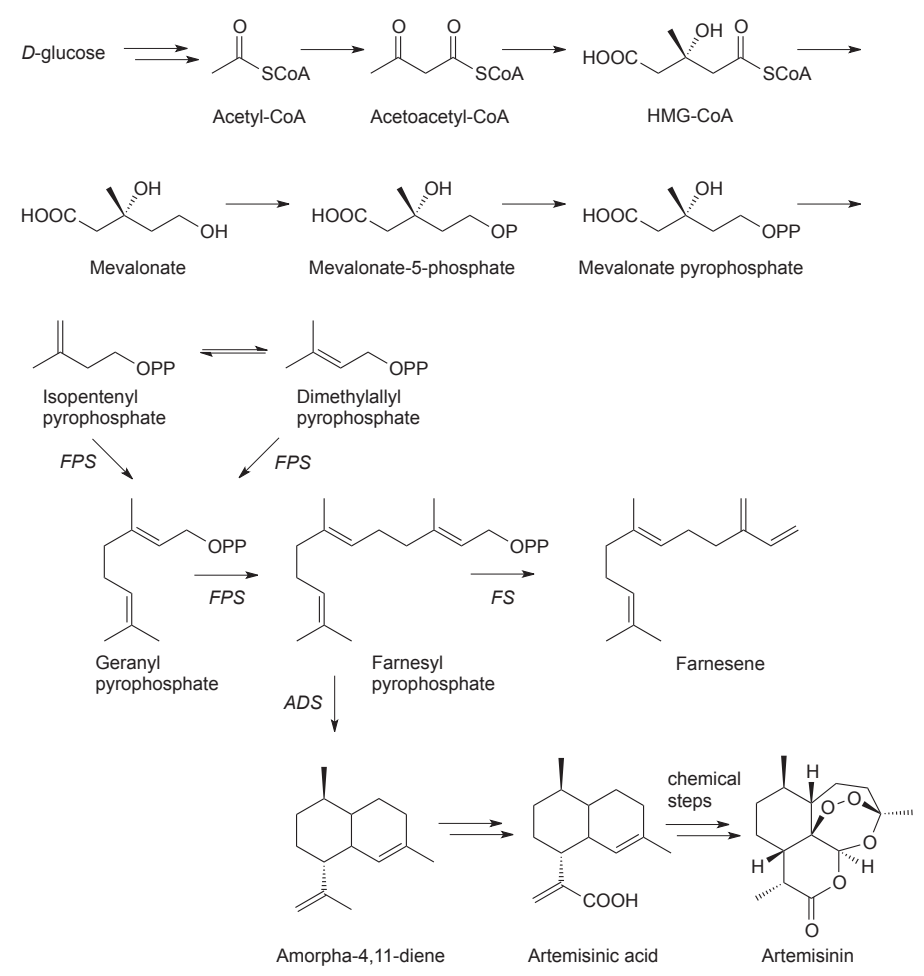

Scheme 2. Metabolic pathway from D-glucose to artemisinic acid or farnesene by engineered yeast.

With regard to materials, the companies Amyris and Kuraray have developed a farnesene-styrene copolymer which is used for the manufacture of a rubber composition with improved handling stability for tires with enhanced properties, such as e.g. a better balance between grip performance and low fuel consumption. ${ }^{8]}$

Furthermore, from a hydrogenated farnesene-styrene block copolymer a thermoplastic elastomer composition can be produced with astonishing properties such as high flexibility, tensile strength, moldability, heat and weather resistance and of a laminated structure. [9]

Starting with the development of a yeast strain for fermentative production of artemisinic acid, the company Amyris enabled the fermentative production of another isoprenoid, trans- $\beta$-farnesene [(6E)-7,11-dimethyl-3-methylidenedodeca-1,6,10-triene, hereafter referred to as simply farnesene] based on the pathway shown in Scheme 2. [10]

In contrast to artemisinic acid which usually reaches a price above $100 \$$ per $\mathrm{kg}$, farnesene can be obtained for a significantly lower price often below $\$ 10$ per $\mathrm{kg}$. For these high volumes and low cost product categories, fermentative production requires extensive developments. These are only possible by applying modern biology tools enabling very high sugar yields, titers and productivities. In the case of farnesene, the central carbon metabolism in $S$. cerevisiae was rewired, in addition to replacing the amorphadiene synthase (ADS) applied in artemisinic acid production with a farnesene synthase (FS). As a result of the seminal metabolic engineering work of Amyris' scientists, a production strain was developed using more than 30 rounds of strain improvement leading to increased cytosolic acetyl coenzyme A (acetyl-CoA) supply, reduced ATP requirement, a reduced loss of carbon to $\mathrm{CO}_{2}$-emitting reactions, an improved redox balance and a $75 \%$ reduced oxygen demand. ${ }^{[11]}$ In addition to the above mentioned strain and process development, the choice of sugar source has a strong impact on the cost as well as on the greenhouse gas $(\mathrm{GHG})$ emissions. The combination of lower cost and GHG emissions led to the selection of Brazilian sugar cane as the preferred carbon feedstock and Brotas (Brazil) as manufacturing site. All these Amyris developments were recognized with a United States Environmental Protection Agency (EPA) Presidential Green Chemistry Challenge Award in 2014. ${ }^{[12]}$ In 2017 , the Brotas site was acquired by DSM which is producing farnesene as an intermediate for nutritional as well as fragrance products

One of many applications of farnesene is its use as starting material in the side-chain synthesis of (all-rac)- $\alpha$-tocopherol. From an industrial point of view (all-rac)- $\alpha$-tocopherol, an equimolar mixture of all eight stereoisomers is the most important representative of the compound class of vitamin $\mathrm{E}$, a group of fat-soluble substances exerting an antioxidative effect with a production volume of $\geq 75^{\prime} 000 \mathrm{t}$ worldwide in $2019 .{ }^{[13]}$ In the fossil sourcebased industrial process to the (all-rac)- $\alpha$-tocopherol side chain acetylene and acetone are connected in four repetitions of $\mathrm{C}_{2}$ - and $\mathrm{C}_{3}$-elongation. ${ }^{[14]}$ In the first step of the recently developed route from farnesene, a $\mathrm{Rh}$-catalyzed $\mathrm{C}_{3}$-elongation reaction using a $\beta$-keto ester results in the formation of a $\mathrm{C}_{18}$-ketone (Scheme 3 ). This transformation links the 'new' starting material to an intermediate known for (all-rac)- $\alpha$-tocopherol production processes. In this reaction tris(sodium-meta-sulfonatophenyl) phosphine is applied as ligand which allows the efficient recovery of the rhodium catalyst in a biphasic solvent system. The reaction itself is conducted in an alcohol/water mixture. The obtained $\beta$-ketoester is converted via saponification and decarboxylation to the desired unsaturated $\mathrm{C}_{18}$-ketone. ${ }^{[15-18]}$ This process is based on the work of the company Adisseo (formerly Rhône-Poulenc) which had already changed their process in the late $1980 \mathrm{~s}$ and used the $\mathrm{C}_{10^{-}}$ compound myrcene as starting material.[19]

The unsaturated $\mathrm{C}_{18}$-ketone is further converted to hexahydrofarnesylacetone by hydrogenation. After synthesis of isophytol and condensation with trimethyl hydroquinone (all-rac)- $\alpha$ tocopherol is obtained (Scheme 3). ${ }^{[20]}$
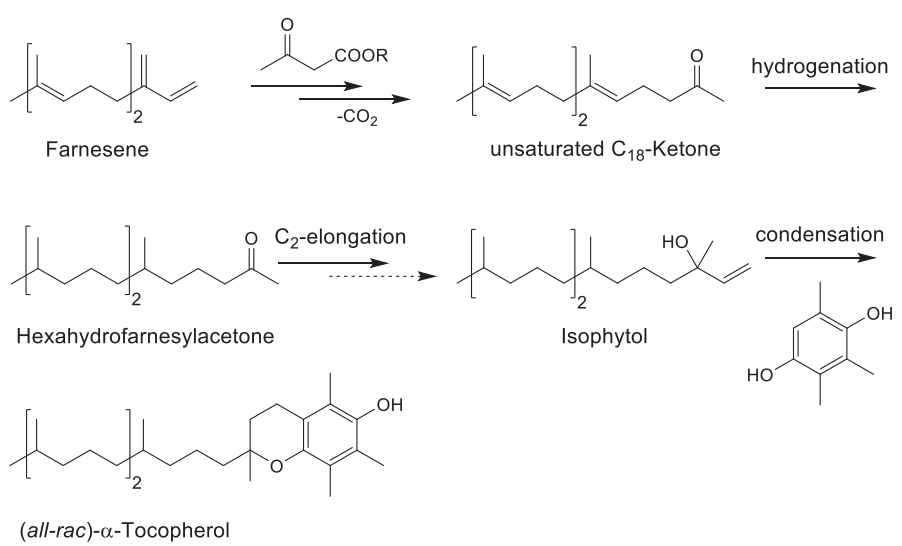

Scheme 3. Synthesis of (all-rac)- $\alpha$-tocopherol using farnesene as starting material. 
Additionally, farnesene serves as a versatile raw material for the production of various fine chemicals in a broad field of applications. A prominent example is the formation of (-)-ambrox from farnesene via homofarnesol (Scheme 4). [21] The synthesis sequence is a combination of chemical synthesis and biocatalysis. It starts with a Rh-catalyzed hydroformylation of farnesene to yield a product mixture containing isohomofarnesal to at least $50 \mathrm{wt} \%$. The aldehyde function of isohomofarnesal is subsequently being reduced to the corresponding alcohol in a Ru-catalyzed transfer hydrogenation. Afterwards, a proton shift to the methylene group is accomplished by a Ru-catalyzed isomerization reaction which forms the tri-substituted double bond. The obtained homofarnesol is then enzymatically cyclized to ambrox using squalene hopene cyclase (Alicyclobacillus acidocaldarius). The biocatalytic step from homofarnesol to (-)-ambrox was implemented on industrial scale by the company Givaudan for applications in the fragrance industry (Scheme 4). ${ }^{[22]}$
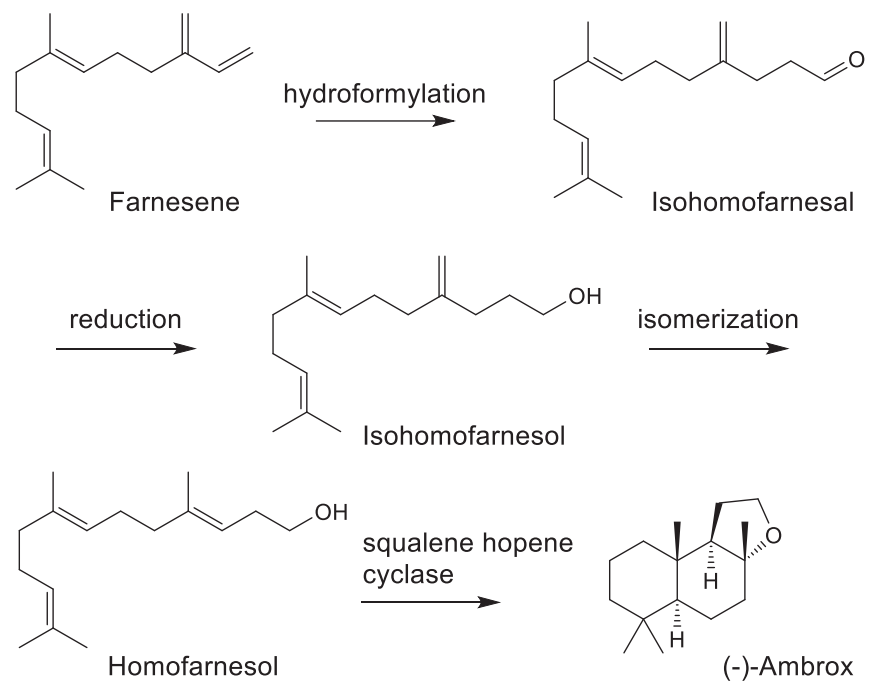

Scheme 4. Synthesis sequence from farnesene to (-)-ambrox.

Further potential for the use of farnesene is seen in pharmaceuticals as well as in material sciences, even though the state-ofthe-art for both has not yet evolved to commercialized processes.

The Japanese pharmaceutical company KOWA has developed the acyclic retinoid peretinoin with potential antineoplastic and chemopreventive properties. It can be accessed from farnesene via farnesol, ${ }^{[23]}$ which after $\mathrm{C}_{3}$-elongation of farnesal in a Wittig reaction leads to the corresponding ketone as an E/Z-mixture. [24] Subsequent reaction with cyanoacetic acid affords first the nitrile and then the acid peretinoin (Scheme 5). [25]

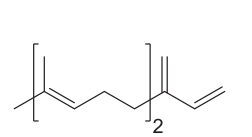

Farnesene<smiles>C=C(C)C=CCC(=C)CC=O</smiles>

$$
\text { a) BuLi, }
$$
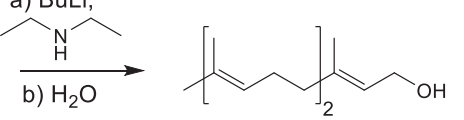

oxidation

\section{Wittig}

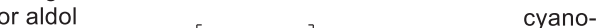

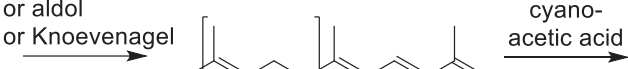

$$
\text { Farnesal }
$$

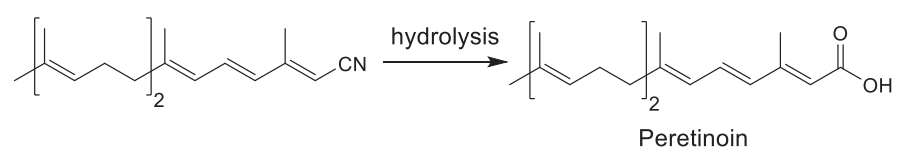

Scheme 5. Synthesis of peretinoin from farnesene.
Moreover, biobased monomers, such as farnesene or $\beta$-myrcene in combination with sunflower oil provide access to a series of novel networks with different compositions (SxF100- $\mathrm{x}$ and SxM100- x). Whereas materials prepared with $100 \%$ terpenes (PF100 and PM100) are very hard and brittle, those made from vegetable oil (PS100) are tearable. The properties of the new materials are closely linked to the content of terpenes. They exhibit remarkable swelling capacity when immersed e.g. in eugenol, which is an interesting antibacterial compound. The release profile indicated a Fickian diffusion model with the release of $90 \%$ of eugenol in 30 days, providing interesting antibacterial properties to the materials. ${ }^{[26]}$

\section{Vitamin $D_{3}$}

Cholesterol plays an important role in humans as a precursor to an array of steroid hormones as well as vitamin $\mathrm{D}_{3}$. The structural complexity of cholesterol makes the chemical synthesis challenging and expensive which is why extraction from animal sources like bovine spinal cord and wool fat is its predominant in-

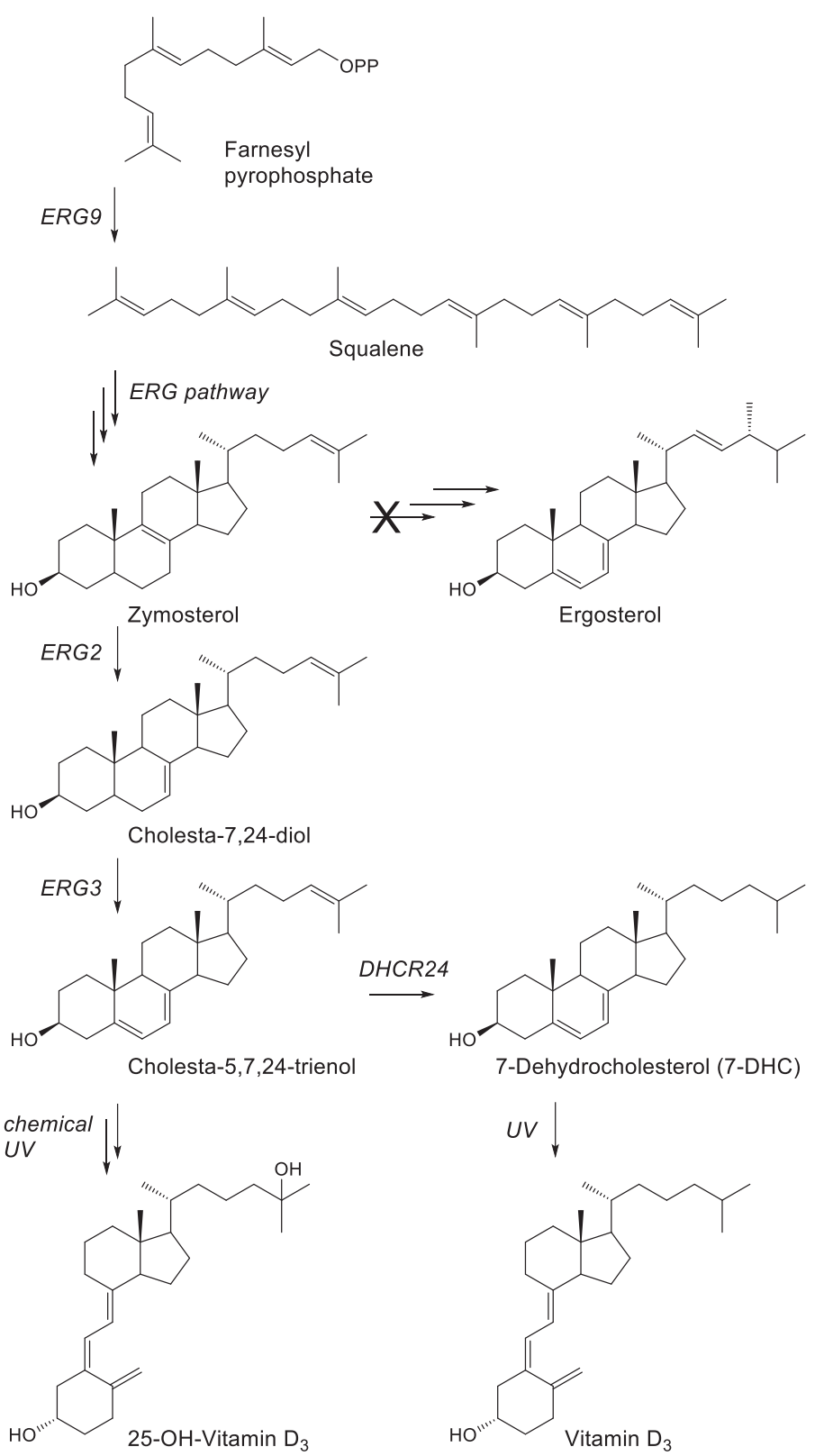

Scheme 6. Metabolic pathway from farnesyl pyrophosphate to cholesta5,7,24-trienol which can be further converted to 7-DHC and with a photochemical step to vitamin $\mathrm{D}_{3}$ or directly to $25-\mathrm{OH}$-vitamin $\mathrm{D}_{3}$ via chemical and one photochemical steps. 
dustrial source. In addition to these animal sources, yeast has been recognized as a promising microorganism for cholesterol derived steroid bioproduction. ${ }^{[27]}$ For the synthesis of vitamin $\mathrm{D}_{3}, 7$-dehydrocholesterol (7-DHC) is an important intermediate which after UV-radiation delivers vitamin $\mathrm{D}_{3}$ as further described below. In 2002 BASF reported on 7-DHC production using a recombinant yeast which contained human and mouse $\mathrm{C}-8$ sterol isomerase, C-5 sterol desaturase and a sterol reductase together with deleted sterol-24-methyltransferase and sterol-22-desaturase genes based on the simplified ERG pathway shown in Scheme 6. ${ }^{[28]}$

Additional improvements were reported by Yuan et al. who addressed imbalances in co-factors caused by the introduction of oxidoreductases with different NAD or NADP co-factor selectivity. ${ }^{[29]}$ By decoupling 7-DHC production from cell growth via different promoter systems and up-regulating several mevalonate (MVA) pathway genes such as acetyl-CoA-acetyltransferase, hydroxymethylglutaryl-CoA-synthase, 3-hydroxy-3-methylglutaryl-CoA-reductase, mevalonate kinase, phosphomevalonate kinase, mevalonate-diphosphate-decarboxylase, isopentyl-diphosphate-isomerase, farnesylpyrophosphate-synthase and introducing a sterol-24-reductase from Gallus gallus, the same group reported further improvements, resulting in significant 7-DHC titers of $1.07 \mathrm{~g} / \mathrm{L}$ in a 5 -L bioreactor. ${ }^{[30]}$ Such improvements provided 7-DHC as a relevant intermediate for the industrial production of vitamin $\mathrm{D}_{3}$. In addition, by blocking the 24-dehydrocholesterol reductase step, one can access cholesta-5,7,24-trienol by fermentation which can be further converted to $25-\mathrm{OH}$-vitamin $\mathrm{D}_{3}$ (Calcidiol).

In the fermentation process not only the target precursor cholesta-5,7,24-trienol is produced but many more steroids. These are present as a complex mixture in the broth and need to be removed. Most of them have no 5,7-diene functionality. The separation can be achieved by the formation of a Diels-Alder adduct of a steroid with a 5,7-diene functionality and a dienophile. This elegant derivatization not only alters the physical properties of the target steroid, but also acts as protecting group of the diene functionality for further downstream processing. For instance, phthalhydrazide is oxidized to the corresponding dienophile and reacted in situ with the diene of the steroid, forming the more polar Diels-Alder adduct. Separation of latter can be achieved by chromatography. $N$-substituted 1,2,4-triazoline-3,5-dione can be used in the DielsAlder reaction as well (Scheme 7).

With regard to phthalhydrazide the advantage of these highly reactive dienophiles is their stability in the oxidized form. This offers the possibility to separate the dienophile activation from the Diels-Alder reaction, simplifying the purification of the DielsAlder adduct and increasing the yield. For instance phenylurazole can be oxidized in the presence of an amine base with inexpensive trichlorisocyanuric acid (TCICA) to 4-phenyl-1,2,4-triazo-

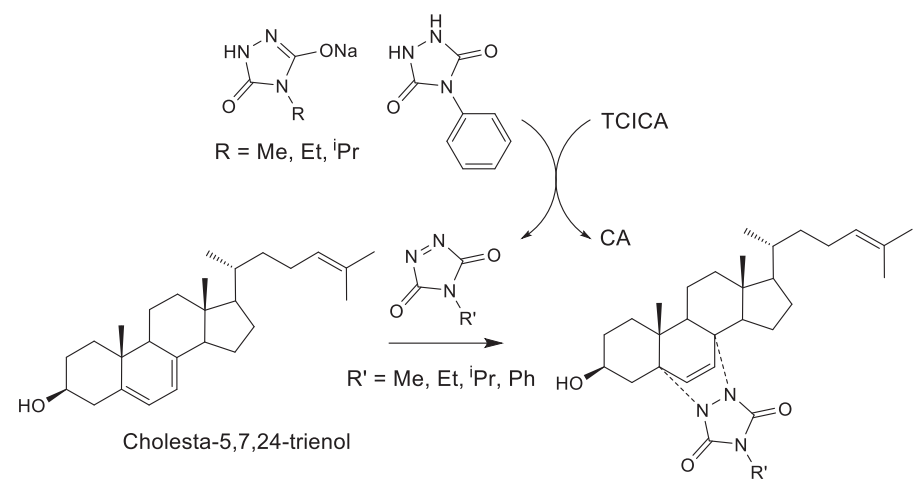

Scheme 7. Diels-Alder reaction of activated urazole derivatives with cholesta-5,7,24-trienol. line-3,5-dione. Formed cyanuric acid (CA) and ammonium chloride waste are filtered off, and the resulting bright red solution is added to the steroid extract. The immediately formed Diels-Alder adduct precipitates and is separated from the extract by filtration in $93 \%$ yield. ${ }^{[31]} \mathrm{N}$-methyl, -ethyl or -isopropyl urazoles as more atom-economic urazoles can also be used, leading to the corresponding Diels-Alder adduct in $91 \%, 13 \%$ and $92 \%$ yield respectively. For the alkyl substituted urazoles the monosodium salts of the corresponding urazoles are used, leading to almost identical results compared to the application of the free urazoles. However, this change offers the possibility to significantly simplify and improve the product isolation in the dienophile precursor process. ${ }^{[32]}$

The resulting Diels-Alder adduct is then oxidized to the corresponding 24-epoxide with meta-chloroperoxybenzoic acid ( $m \mathrm{CP}$ BA) in high yield (Scheme 8). Reduction with $\mathrm{LiAlH}_{4}$ first cleaves the urazole moiety followed by the in situ regioselective epoxide opening to form 25-OH-7-dehydrocholesterol.

25-OH-Vitamin $\mathrm{D}_{3}$ is produced by photolysis of the 5,7-diene system by irradiation with ultraviolet light at an absorption maximum of between 270 and $280 \mathrm{~nm}$. The formed 25-OH-previtamin $\mathrm{D}_{3}$ is in equilibrium with its ring closure photoproducts - the starting diene, its diastereomer 25-OH-lumisterol and the product of
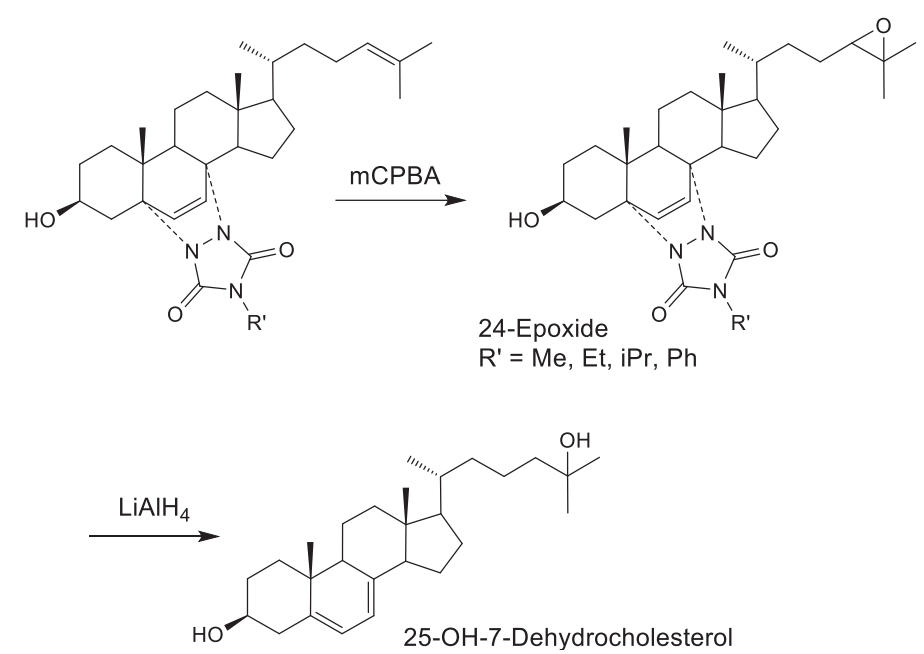

Scheme 8. Oxidation and reduction of the Diels-Alder adduct.
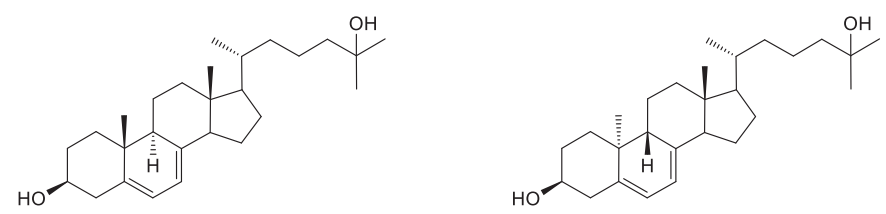

25-OH-7-Dehydrocholestero 25-OH-Lumisterol

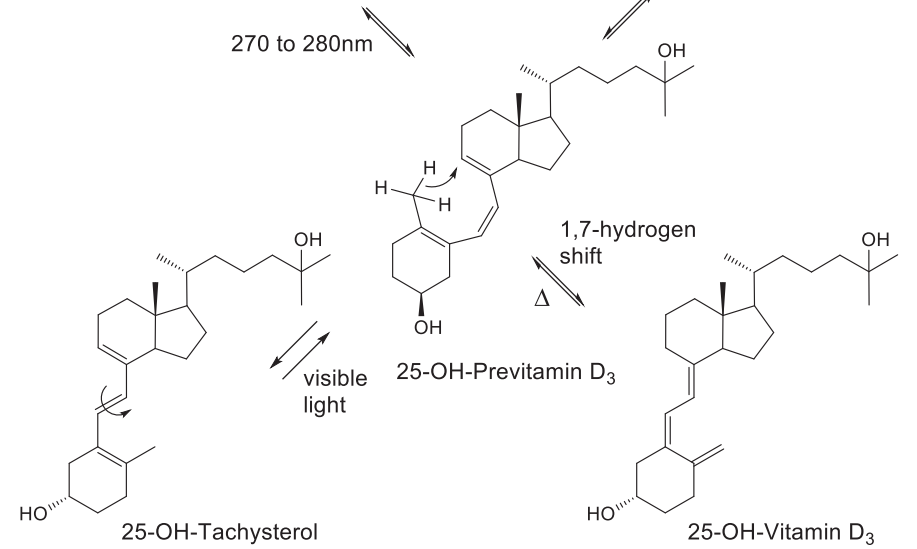

Scheme 9. Photochemistry of 25-OH-7-dehydrocholesterol to $25-\mathrm{OH}-$ vitamin $\mathrm{D}_{3}$. 
E/Z photoisomerization 25-OH-tachysterol (Scheme 9). Whereas the over-irradiation product 25-OH-tachysterol can be isomerized back to 25-OH-previtamin $\mathrm{D}_{3}$, it is economically not worthwhile to recycle 25-OH-lumisterol, and this side product is lost. To minimize yield loss, photolysis is discontinued after 40 to $60 \%$ turnover of the starting diene. The isomerization of $25-\mathrm{OH}$-tachysterol to 25-OH-previtamin $\mathrm{D}_{3}$ is performed with visible light, using a photosensitizer. The last step, the thermal isomerization of 25-OH-previtamin $\mathrm{D}_{3}$ to $25-\mathrm{OH}$-vitamin $\mathrm{D}_{3}$ is a reversible sigmatropic 1,7-hydrogen shift from C-9 to C-19 performed by heating the solution at 60 to $80{ }^{\circ} \mathrm{C}$. Final crystallization provides $25-\mathrm{OH}$ vitamin $\mathrm{D}_{3}$ in highly purified form.

\section{Furfural (FF) and Levulinic Acid (LA)}

Furfural as a platform chemical has been derived from sugars as renewable resource for decades (Scheme 10). Since the early 1920s FF has been industrially used as platform for $\mathrm{C}_{5}$ building blocks. Under pressure and elevated temperatures in the presence of acid, pentoses are transformed to FF. ${ }^{[33-35]}$ FF has been used as building block for Nylon-6 by Dupont since 1960 . LA can be produced from hexoses by heating under acidic conditions via hydration of intermediate 5-hydroxymethylfurfural (5-HMF) with simultaneous formation of formic acid.

Most often applied conditions to produce LA and FF are high temperatures $\left(120-200{ }^{\circ} \mathrm{C}\right)$ in homogeneous mineral acids $(<10$ wt\% e.g. $5 \mathrm{wt} \%$ ) like $\mathrm{H}_{2} \mathrm{SO}_{4}$ or $\mathrm{HCl}$ with reaction times up to a few hours. Most steps in the reaction chains are around first order in acid and the carbohydrates/furans, with activation energies in the range of 90-160 kJ/mol, meaning 2-2.5 times faster reaction rates per $10{ }^{\circ} \mathrm{C}$ that can be derived using the Arrhenius equation applied at the relevant temperature range. ${ }^{[36-40]}$ Typical molar yields in clean hexose systems catalyzed by diluted $\mathrm{H}_{2} \mathrm{SO}_{4}$ are around $60 \mathrm{~mol} \%$ for $\mathrm{C}_{6}$ to $5-\mathrm{HMF}$, and $90 \mathrm{~mol} \%$ for $5-\mathrm{HMF}$ to LA. Overall molar yields under dilute $\mathrm{HCl}$ catalyzed conditions are significantly higher (1.3-1.4 times). ${ }^{[36]}$ Loss of yield is due to degradation to humins, being a furan-rich oligomer network formed from the carbohydrates and furans. ${ }^{[41]}$

Next to the homogeneous mineral acids many acidic catalysts have been applied for the chemical hydrolysis and dehydration steps, such as organic acids (e.g. oxalic acid), salts (e.g. $\left.\left(\mathrm{NH}_{4}\right)_{2} \mathrm{SO}_{4} / \mathrm{SO}_{3}\right)$, Lewis acids $\left(e . g . \mathrm{AlCl}_{3}\right)$ and the others (e.g. ion-exchange resins). ${ }^{[42]}$ Both Lewis and Brønsted acidity of the catalysts affects product distribution (see Scheme 10), e.g. glucose dehydration is primarily Brønsted acid catalyzed, while the intermediate fructose dehydration is both Lewis and Brønsted catalyzed. ${ }^{[36,43-45]}$ The heterogeneous catalysts have advantages of higher yield, product/catalyst recovery, corrosion and wastewater amount, but face issues on the lengthy reaction time and deactivation and fouling by the humins/char/ lignin. ${ }^{442-46]}$

DSM has developed a lignocellulosic biorefinery for LA production catalyzed by homogeneous mineral acids. ${ }^{[47-51]} \mathrm{Big}$ challenges have to be addressed in the initial steps before obtaining the purified platform chemicals ready for upgrading by 'regular' chemical processing:

- Desanding and destoning of harvested lignocellulosic feedstocks appears trivial, but is prerequisite to allow for processing in reactor-systems, both from a plugging and abrasion perspective. Woody feedstocks, being rather clean, have an advantage here.

- Good sizing of the lignocellulosic feedstocks is key for processing e.g. in the paper\&pulp derived screw type Pandia reactors ${ }^{[52]}$ or slurry reactors. ${ }^{[42]}$ Fibrous nature of feedstocks can unfavorably limit upper dry matter content in processing.

- Construction materials that resist both high temperature acidic conditions and abrasion in the reactor and feed systems are hardly developed (compared with the brick-lined 100-year old Quaker Oats process for FF. ${ }^{[34]}$ ) This negatively impacts process economics.

- Insoluble and soluble humins/char formation, e.g. up to half of the feed, can disturb processing by their phase behavior in separations and by equipment fouling due to stickiness.

- The high mineral acid concentration require recovery, which could be performed by solvent extraction of the platform chemicals. [53]

- The downstream processing needs to be carefully designed to deal with complex mixtures having various azeotropes and angelica lactone formation from LA. ${ }^{51]}$

LA is one of the most utilized biomass-based platform molecules. It is used as starting material for various bulk chemicals, such as polymers, resins and fuel additives. ${ }^{[54]}$ LA esters, e.g. the methyl, ethyl and n-butyl levulinate can be used as diesel additives. ${ }^{[5,56]}$ LA or its esters can also be hydrogenated to $\gamma$-valerolactone (GVL) which has excellent properties as a solvent ${ }^{[57,58]}$ and can be used as a raw material for nylon intermediates, ${ }^{[59-62]}$ a fuel additive, ${ }^{[63,64]}$ and for high value chemicals ${ }^{[65-68]}$ (Scheme 10). GVL has a sweet, creamy and nutty taste and smell and is therefore applied in the flavor and fragrance industry. It enhances for instance the flavor of coconut, vanilla, toffee, milk chocolate, and milk. ${ }^{[69]}$ The hydrogenation of LA to GVL is catalyzed by homogeneous ${ }^{[70]}$ or heterogeneous catalysts ${ }^{[71]}$ in the liquid phase. ${ }^{[72,73]}$ On the other hand, continuous gas-phase hydrogenation of LA to GVL has been far less studied. Gas-phase processes have several advantages over liquid-phase processes. They are especially suited for continuous processes and are often highly selective. Mass transfer effects are usually less pronounced, and in most cases no solvent is used. Therefore, no energy intensive separation of solvents is required during work-up. Scale-up of gas-phase reactions is generally quite straightforward because large-scale reactors are usually equipped with a large number of small reactors, e.g. tube bundle reactors, which have similar physical properties to the small-scale equipment. The energy balance compared to a liquid-phase process is in some cases similar because of a better heat recovery at high temperatures. In most gasphase hydrogenation reactions atmospheric hydrogen pressure is applied in contrast to most liquid phase hydrogenations where pressure equipment is required due to higher hydrogen pressures.

Supported $\mathrm{Ni},{ }^{[74,75]} \mathrm{Ru}, \mathrm{Pd}$, and $\mathrm{Pt}$ catalysts, ${ }^{[76]} \mathrm{Zr}$ on $\beta$-zeolite, ${ }^{[77]}$ and $\mathrm{Cu}, \mathrm{Re}, \mathrm{Ir}, \mathrm{Rh}$, and $\mathrm{Au}^{[71,78]}$ based catalysts were studied previously in the gas-phase hydrogenation of LA to GVL. Depending on the chosen reaction conditions and catalyst up to 99\% yield could be achieved.

At DSM commercially available $\mathrm{Ru}$ - and $\mathrm{Cu}$-based catalysts were screened for the gas-phase hydrogenation of LA to GVL in order to find a catalyst system and reaction conditions which are suitable for large-scale industrial production. ${ }^{[79]}$ Compared to $\mathrm{Cu}$-based catalysts, the activity and stability of $\mathrm{Ru} / \mathrm{C}$ and $\mathrm{Ru} /$ $\mathrm{Al}_{2} \mathrm{O}_{3}$ were not satisfactory. Therefore, further emphasis was put on copper-based catalysts.

The conversion of LA to GVL was tested with a copper chromite catalyst with neat LA and $3 \%$ water at $290{ }^{\circ} \mathrm{C}$. The weight hourly space velocity (WHSV) was set to $0.65-1.30 \mathrm{~h}^{-1}$ and the mol equiv. of hydrogen to 22-44:1. Constant yields of $c a .75 \%$ were obtained for $28 \mathrm{~h}$ before the conversion dropped from $>95 \%$ to $<50 \%$ due to coke formation on the catalyst. When $\mathrm{CuO} / \mathrm{ZnO}-$ based catalysts were applied even faster deactivation occurred.

Copper oxide-based catalysts (50-70\% Cu-oxide, 10-30\% $\mathrm{SiO}_{2}$ ) were applied in the reaction with neat $\mathrm{LA}$ and $3 \%$ water at $280{ }^{\circ} \mathrm{C}$. The best catalyst/reaction condition system showed constant activity and selectivity for nearly $90 \mathrm{~h}$ (WHSV $=1.62$ $\mathrm{h}^{-1}, 290^{\circ} \mathrm{C}$; LA : $\mathrm{H}_{2}=1$ : 16; feed: LA and $6 \mathrm{wt} \%$ water). Over-hydrogenation to 1-pentanol was observed only in small amounts. Deactivation of the catalyst might be due to hot spots or polymer formation which may lead to clogging of the pores 
of the catalyst. Once the entire catalyst bed is deactivated the yield decreases sharply. For an industrial application the lifetime of the catalyst and the selectivity still need to be further optimized.

The aromatic $\mathrm{C}_{6}$-building block 5-hydroxymethylfurfural (5HMF) is accessible from hexoses via the same pathway as FF from pentoses (see Scheme 10). ${ }^{[80,81]}$ 5-HMF gives access to a broad range of platform chemicals. An important representative is 2,5-dimethylfuran (2,5-DMF), which is seen as component of biobased fuel. ${ }^{[82]}$ Within studies to replace fossil raw materials by renewable materials for vitamin manufacture, the access to the aromatic (all-rac)- $\alpha$-tocopherol building block 2,3,6-trimethylphenol (2,3,6-TMP) by isomerization of furans such as 2,5-DMF was studied by DSM.

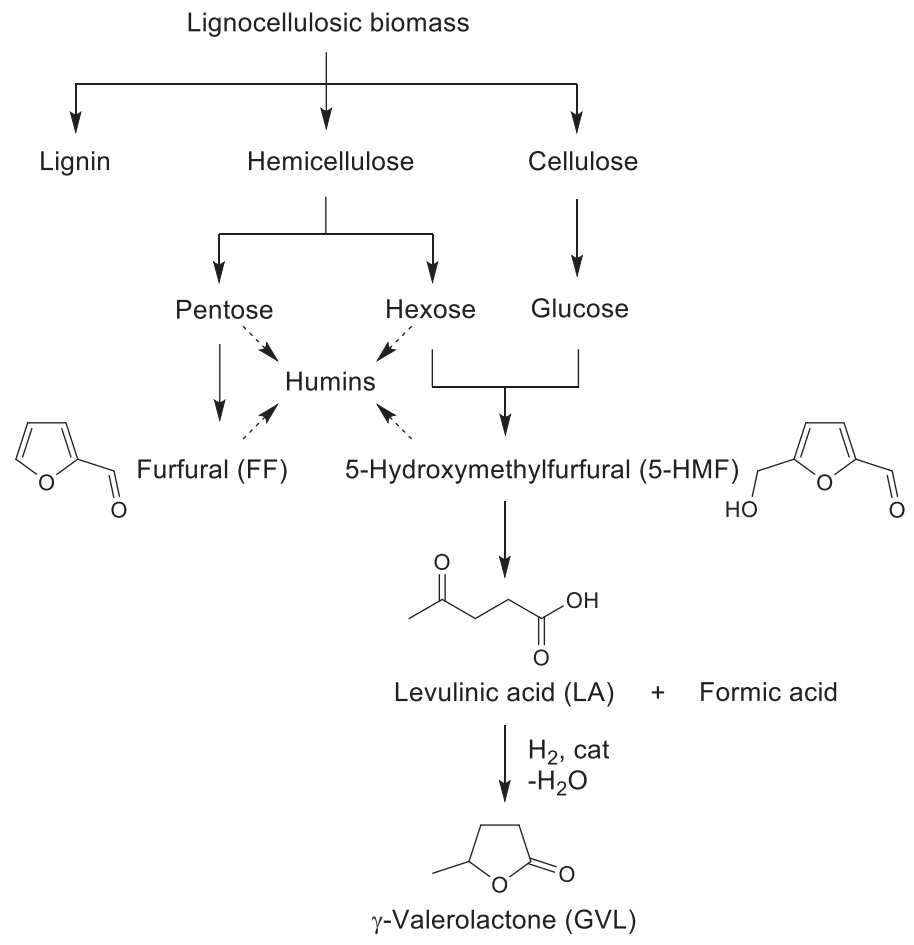

Scheme 10. Production of chemicals from lignocellulosic biomass.

Today, (all-rac)- $\alpha$-tocopherol is manufactured from the two building blocks 2,3,5-trimethylhydroquinone (2,3,5-TMHQ) and isophytol (Scheme 11). ${ }^{[20]}$ 2,3,6-TMP is a key intermediate for construction of 2,3,5-TMHQ. Traditionally, 2,3,6-TMP is made from $m$-cresol, which is available from coal tar.<smiles>Cc1ccc(C)c(O)c1C</smiles>

2,3,6-TMP

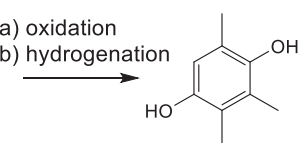

2,3,5-TMHQ

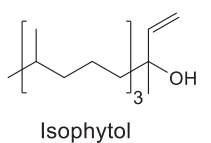

$$
\text { Isophytol }
$$

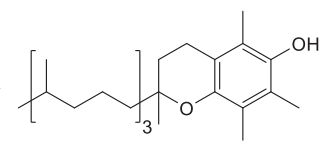

(all-rac)- $\alpha$-Tocopherol
Scheme 11. Industrial manufacture of (all-rac)- $\alpha$-tocopherol by condensation of isophytol and 2,3,5-trimethylhydroquinone.

The isomerization of furans to phenols has been concomitantly discovered and described by Hashmi and Echavarren in the early

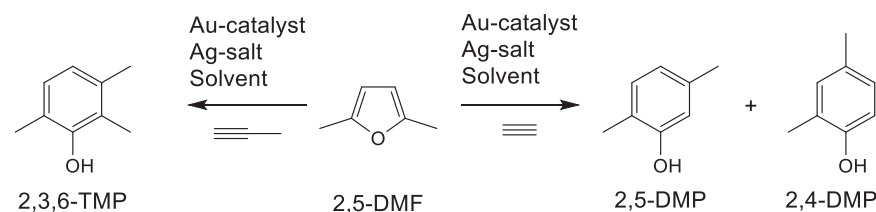

Scheme 12. Intermolecular furan-alkyne isomerization with gaseous alkynes.

2000s. ${ }^{[83]}$ It is a special type of transition metal catalyzed isomerization reactions of the $\alpha, \omega$-enynes studied (Scheme 12). ${ }^{[84]}$

Alkynyl furans rearrange in the presence of transition metal catalysts to the corresponding phenols, where the two alkyne carbons are incorporated next to the hydroxyl group of the phenol. The reaction is initiated by para-coordination of the carbophilic transition metal ion to the carbon-carbon triple bond reducing its electron density.

A closely positioned carbon-carbon double bond reacts as a nucleophile and leads to a three-membered cyclic intermediate. The intermediate opens to a transition metal carbene (disputed, could be a stabilized cationic intermediate). Then the ring closes to the tautomeric benzene oxide and oxepine, which rearranges to the phenol. Several functional groups are tolerated. ${ }^{[85]}$ This reaction has been applied in an intermolecular fashion by Hashmi, ${ }^{[86]}$ and later Huguet et al. ${ }^{[87]}$ with excellent yields especially using low functionalized alkynes.

The scope of the furan phenol isomerization was successfully extended to the use of gaseous alkynes such as acetylene and propyne for the synthesis of trimethylphenol.

Both gaseous alkynes - acetylene and propyne - must be handled under ambient pressure. Especially acetylene is very sensitive to increased pressure, as it undergoes violent decomposition under pressures greater than 1.6 bar. ${ }^{[88]}$

A broad screening of reaction conditions, catalysts and counter-ions allowed the determination of highly suitable conditions for the synthesis of 2,5-dimethylphenol (2,5-DMP) from 2,5DMF and acetylene. ${ }^{[89]}$

Interestingly, the reaction afforded a product mixture of 2,5DMP and 2,4-DMP (Scheme 12, right). Ligands with high electron density favored the 2,4-isomer, ligands with less electron donating character favored formation of the 2,5-DMP. We explain the formation of the 2,4-DMP with methyl group migration in the
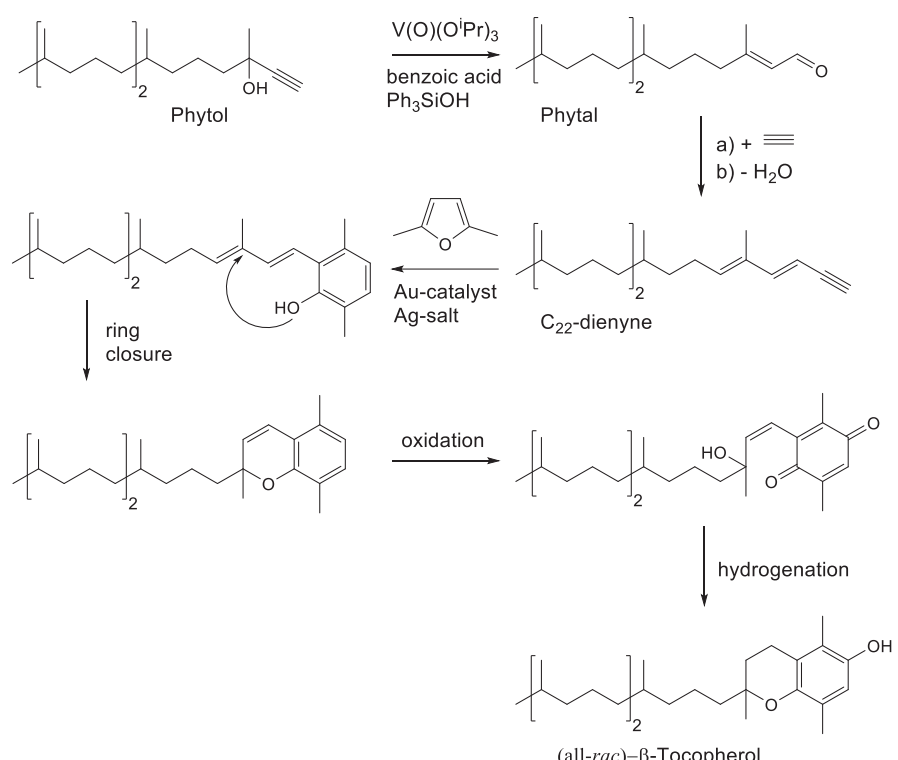

(all-rac)- $\beta$-Tocopherol

Scheme 13. (all-rac)- $\beta$-Tocopherol synthesis from dimethylfuran and $\mathrm{C}_{22}$-dienyne. 
benzene oxide intermediate. This hypothesis agrees with observation of alkyl group migration in benzene oxides in the presence of traces of acid. ${ }^{[90]}$ The reaction of propyne in place of acetylene led to a much cleaner reaction and higher selectivity ${ }^{[1]}$ (Scheme 12 , left).

Methyl group migration was observed to a very low extent $(<5 \%)$ and hydroarylation, a frequently observed side-reaction in the intramolecular reaction, ${ }^{[92]}$ was not observed at all. The obtained 2,3,6-TMP is used via the usual ways towards (all-rac)$\alpha$-tocopherol. ${ }^{[14,20]}$

Another access to (all-rac)- $\alpha$-tocopherol from renewable furans uses long chain alkynes such as a $\mathrm{C}_{22}$-dienyne (Scheme 13). ${ }^{[93]}$ The side-chain is constructed starting from phytol which can be oxidized to phytal. After addition of acetylene and dehydration, a $\mathrm{C}_{22}$ dienyne is obtained and easily converted with 2,5DMF to the desired phenol. Acid catalyzed ring closure to the corresponding chromane, then oxidation to the quinone, followed by hydrogenation gave access to (all-rac)- $\beta$-tocopherol.

\section{Conclusions}

The above examples highlight new approaches to implement manufacturing processes in the fine chemical industry, especially in the nutritional industry, starting from a renewable feedstock. To fulfill the requirements of modern and sustainable production processes and products new catalysts and methodologies will be required to create further value of renewable feedstocks and continuously shift to more environmentally friendly production processes for active nutritional compounds.

In addition, active ingredients need to be transferred into suitable product forms. In the following article in the same issue of this journal, we demonstrate how hydrocolloids derived from renewable plant sources can contribute to conform to the unequivocal demand for a carbon neutral society.

\section{Acknowledgements}

The authors gratefully acknowledge everybody who contributed to the work presented in this article.

Received: May 21, 2021

[1] G. Pappenberger, H.-P. Hohmann, Adv. Biochem. Eng. Biotechnol. 2014, 143, 143, https://doi.org/10.1007/10_2013_243.

[2] T. Reichstein T. A. Grüssner, Helv. Chim. Acta 1934, 7, 311, https://doi.org/10.1002/hlca.19340170136.

[3] J. L. Kenneth, T. L. Jay, Proc. Natl. Acad. Sci. USA 2016, 113, 5970, https://doi.org/10.1073/pnas.1521291113.

[4] Nagoya-Protocol, www.cbd.int/abs/about/, accessed April 27th, 2021

[5] P. G. M. Van Loon, Adolphus, H. P. Hohmann, W. Bretzel, M. Huembelin, M. Pfister, Chimia 1996, 50, 410 .

[6] A. Goossens, P. Arendt, N. Callewaert, PCT Int. Appl. WO 2018096150 A1 2018.

[7] a) K. Fisher, D. McPhee, F. X. Woolard, WO Patent Appl. No.WO 2009088404 A1 20090716; 2009; b) K. Reiling, K. Keith, S. Renninger, D. J. Mcphee, K. J. Fisher, D. A. Ockey, WO Patent Appl. No. WO 2006128126 A1, 2006.

[8] D. Koda, M. Hirata, H. Marui, JP 2017014373 A 2017.

[9] H. Sasaki, D. Konishi, JP 2018024776 A 2018.

[10] K. R. Benjamin, I. R. Silva, J. P. Cherubim, D. McPhee, C. J. Paddon, J. Braz. Chem. Soc. 2016, 27, 1339, https://doi.org/10.5935/0103-5053.20160119.

[11] A. L. Meadows, K. M. Hawkins, Y. Tsegaye, E. Antipov, Y. Kim, L. Raetz, R. H. Dahl, A. Tai, T. Mahatdejkul-Meadows, L. Xu, L. Zhao, M. S. Dasika, A. Murarka, J. Lenihan, D. Eng, J. S. Leng, C.-L. Liu, J. W. Wenger, H. Jiang, L. Chao, P. Westfall, J. Lai, S. Ganesan, P. Jackson, R. Mans, D. Platt, C. D. Reeves, P. R. Saija, G. Wichmann, V. F. Holmes, K. Benjamin, P. W. Hill, T. S. Gardner, A. E. Tsong, Nature 2016, 537, 694, https://doi.org/10.1038/nature19769.

[12] Presidential Green Chemistry Award, www.epa.gov/greenchemistry/presidential-green-chemistry-challenge-2014-small-business-award, accessed February 28th, 2021.

[13] W. Bonrath, A. Wyss, G. Litta, K.-U. Baldenius, L. von dem BusscheHünnefeld, E. Hilgemann, P. Hoppe, R. Stürmer, T. Netscher, 'Ullmann's Encyclopedia of Industrial Chemistry', Wiley-VCH Verlag GmbH \& Co. KgaA, Weinheim, to be printed.
[14] W. Bonrath, T. Netscher, Appl. Catal. A 2005, 280, 55, https://doi.org/10.1016/j.apcata.2004.08.026.

[15] Q. Dai, Y. Zhen, L. Chen, et al. CN 105944768 (Nenter \& Co., Inc.) 2016.

[16] M. Schelwies, R. Paciello, H. Eckhardt, M. Dehn, WO Patent Appl. No. WO2015165959 (BASF SE), 2015.

[17] Q. Dai, Y. Zheng, Q. Chen, L. Yao, X. Zhou, P. Liu, CN 105859534 (Nenter \& Co., Inc.), 2016.

[18] R. Beumer, W. Bonrath, J.-M- Delpho, M. Joray, J. A. Medlock, T. Netscher, D. Soriano, R. T. Stemmler, WO Patent Appl. No. WO2019043251, 2019

[19] C. Mercier, P. Chabardes, Pure Appl. Chem. 1994, 66, 1509, http://dx.doi.org/10.1351/pac199466071509.

[20] M. Eggersdorfer, D. Laudert, U. Létinois, T. McClymont, J. Medlock, T. Netscher, W. Bonrath, Angew. Chem. Int. Ed. 2012, 51, 12960, https://doi.org/10.1002/anie.201205886.

[21] J. Strautmann, S. Rüdenauer, C. Rein, M. Weingarten, R. Paciello, W. Siegel, M. Breuer, P. Hofmann, S. Schmidt, US10315975B2, 2019.

[22] E. Eichhorn, E. Locher, S. Guillemer, D. Wahler, L. Fourage, B. Schilling, Adv. Synth. \& Catal. 2018, 360, 2339, https://doi.org/10.1002/adsc.201800132.

[23] M. Inoue, A. Maeda, K. Sakamoto, Jpn. Kokai Tokkyo Koho, JP 2019189566 A, 2019

[24] W. Bonrath, J. A. Medlock, P. Riebel, R. T. Stemmler, WO Patent Appl. No. WO 2017098050 A1, 2017

[25] R. Beumer, WO Patent Appl. No.WO 2012041948 A1, 2012

[26] C. Mangeon, F. Thevenieau, E. Renard, V. Langlois, ACS Sustain. Chem. Eng. 2017, 5, 6707, https://doi.org/10.1021/acssuschemeng.7b00959.

[27] S. Xu, Y. Li; J. Ind. Microbiol. Biot. 2020, 47, 829 , https://doi.org/10.1007/s10295-020-02291-7

[28] C. Lang, M. Veen, WO Patent Appl. No. WO2003064650, 2003.

[29] W. Su, W-H Xiao, Y. Wang, D. Liu, X. Zhou, Y-J Yuan, PLoS ONE 2015 10, e0130840, https://doi.org/10.1371/journal.pone.0130840.

[30] X.-J. Guo, W.-H. Xiao, Y. Wang, M.-D. Yao, B.-X. Zeng, H. Liu, G.-R. Zhao, Y.-J. Yuan, Biotechnol. Biofuels 2018, 11, 192, https://doi.org/10.1186/s13068-018-1194-9

[31] M. Marty, J. Schütz, EP Patent Appl. No. EP19218028.9, 2019.

[32] M. Marty, J. Schütz, EP Patent Appl. No. EP19218026.3, 2019

[33] J.-P. Lange, E. van der Heide, J. van Buijtenen, R. Price, ChemSusChem 2012, 5, 150, https://doi.org/10.1002/cssc.201100648.

[34] 'Ullmann's Encyclopedia of Industrial Chemistry', VCH Weinheim, Vol. 16, 2012, p. 285 https://doi.org/10.1002/14356007.a12_119.pub2.

[35] L. Filiciotto, A. M. Balu, J. C. Van der Waal, R. Luque, Catal. Today 2018, 302, 2, https://doi.org/10.1016/j.cattod.2017.03.008.

[36] B. Girisuta, PhD Thesis Chemical Engineering, University of Groningen, The Netherlands, 2007

[37] B. Girisuta, L. P. B. M. Janssen, H. J. Heeres, Ind. Eng. Chem. Res. 2007, 46, 1696. https://doi.org/10.1021/ie061186z.

[38] B. Girisuta, L. P. B. M. Janssen, H. J. Heeres, Chem. Eng. Res. Des. 2006, 84, 339, https://doi.org/10.1205/cherd05038.

[39] R. Weingarten, J. Cho, W Curtis Conner, G. W. Huber, Green Chem. 2010, 12, 1423, https://doi.org/10.1039/c003459b.

[40] G. Marcotullio , W. De Jongh, Green Chem. 2010, 12, 1739, https://doi.org/10.1039/b927424c

[41] I. Zandvoort, Y. Wang, C. B. Rasrendra, E. R. H. van Eck, P. C. A. Bruijnincx, H. J. Heeres, B. M. Weckhuysen, ChemSusChem 2013, 6 , 1745, https://doi.org/10.1002/cssc.201300332.

[42] S. Kang, J. Fu, G. Zhang, Renew. Sust. Ener. Rev. 2018, 94, 340, https://doi.org/10.1016/j.rser.2018.06.016.

[43] C. Antonetti, D. Licursi, S. Fulignati, G. Valentini, A. Raspolli Galletti, Catalysts 2016, 6, 196, https://doi.org/10.3390/catal6120196.

[44] L. Covinich, N. Clauser, F. Felissia, M. Vallejos, M. Area, Biofuel. Bioprod. Bioref. 2020, 14, 417, https://doi.org/10.1002/bbb.2062.

[45] P. C. Torres-Mayanga, D. Lachos-Perez, A. Mudhoo, S. Kumar, A. B. Brown, M. Tyufekchiev, G. Dragone, S. I. Mussatto, M. A. Rostagno, M. Timko, T. Forster-Carneiro, Biomass Bioenergy 2019, 130 https://doi.org/10.1016/j.biombioe.2019.105397.

[46] I. Thapa, B. Mullen, A. Saleem, C. Leibig, R. T. Bakera, J. B. Giorgia, Appl. Catal. A: Gen. 2017, 539, 70, https://doi.org/10.1016/j.apcata.2017.03.016.

[47] R. F. M. J. Parton, WO Patent Appl. No. WO2014087015 A1, 2014

[48] R. F. M. J. Parton, M. P. W. M. Rijkers, J. A. Kroon, EP Patent Appl. No. EP2537841 A1, 2012

[49] J. G. De Vries, J. A. Kroon, R. F. M. J. Parton, P. L. Woestenborghs, A. De Rijke, WO Patent Appl. No. WO2014009521 A1, 2014

[50] G. W. A. Hangx, G. J. P. Krooshof, A. De Rijke, WO Patent Appl. No. WO2014184281 A1, 2014.

[51] A. De Rijke, G. W. A. Hangx, R. F. M. J. Parton, B. Engendahl, WO Patent Appl. No. WO2014087013 A1, 2014

[52] C. M. Cai, T. Zhang, R. Kumara, C. E. Wyman, Green Chem. 2013, 15 , 3140, https://doi.org/10.1039/c3gc41214h. 
[53] T. Brouwer, M. Blahusiak, K. Babic, B. Schuur, Sep. Purif. Technol. 2017, 185, 186, https://doi.org/10.1016/j.seppur.2017.05.036.

[54] J. J. Bozell, L. Moens, D. C. Elliott, Y. Wang, G. G. Neuenschwander, S. W. Fitzpatrick, R. J. Bilski, J. L. Jarnefeld, Resour. Conserv. Recycl. 2000, 28, 227, https://doi.org/10.1016/S0921-3449(99)00047-6.

[55] R. Mariscal, D. M. Alonso, 'Levulinic acid and $\gamma$-valerolactone', Chapt. 3.7, pp 169-190 in 'Furfural: An entry point of lignocellulose in biorefineries to produce renewable chemicals, polymers and biofuels', Ed. M. L. Granados, D. M. Alonso, World Scientific Publishing Europe Ltd, 2018, https://doi.org/10.1142/q0142

[56] D. R. Fernandes, A. S. Rocha, E. F. Mai, C. J. A. Mota, V. Teixeira da Silva, Appl. Catal. A: Gen. 2012, 425, 199 https://doi.org/10.1016/j.apcata.2012.03.020.

[57] D. Fegyverneki, L. Orha, G. Láng, I. T. Horváth, Tetrahedron 2010, 66, 1078, https://doi.org/10.1016/j.tet.2009.11.013.

[58] P. G. Jessop, Green Chem. 2011, 13, 1391, https://doi.org/10.1039/C0GC00797H.

[59] L. Lefort, B. Engendahl, J. G. de Vries, EP Patent Appl. No. EP 2816029, 2014.

[60] M. Rose, R. Palkovits, Macromol. Rapid Commun. 2011, 32, 1299, https://doi.org/10.1002/marc.201100230.

[61] R. F. M. J. Parton, M. C. C. Janssen, B. Engendahl, J. G. de Vries, WO Patent Appl. No. WO 2014111446, 2014.

[62] A. de Rijke, G. W. D. Hangx, R. F. M. J. Parton, B. Engendahl B, WO Patent Appl. No.WO 2014087014, 2014

[63] J. Q. Bond, D. M. Alonso , D. Wang, R. M. West, J. A. Dumesic, Science 2010, 327, 1110, https://doi.org/10.1126/science.1184362.

[64] I. T. Horváth, H. Mehdi, V. Fabos, L. Boda, L. T. Mika, Green Chem. 2008, 10, 238, https://doi.org/10.1039/B712863K.

[65] L. E. Manzer, Appl. Catal. A: Gen. 2004, 272, 249, https://doi. org/10.1016/j.apcata.2004.05.048.

[66] D. Cerniauskaite, J. Rousseau, A. Sackus, P. Rollin, A. Tatibouet, Eur. J. Org. Chem. 2011, 2293, https://doi.org/10.1002/ejoc.201001438.

[67] R.-H. Guo, Q. Zhang, Y.-B. Ma, X.-Y. Huang, J. Luo, L.-J. Wang, C.-A. Geng, X.-M. Zhang, J. Zhou, Z.-Y. Jiang, J.-J. Chen, Bioorg. Med. Chem. 2011, 19, 1400, https://doi.org/10.1016/j.bmc.2011.01.006.

[68] I. van der Meulen, E. Gubbels, S. Huijser, R. Sablong, C. E. Koning, A. Heise, R. Duchateau, Macromolecules 2011, 44, 4301, https://doi.org/10.1021/ma200685u.

[69] J. Michalski, J. Perfumer \& Flavorist 2014, 39, 52, https://perfumerflavorist.texterity.com/perfumerflavorist/february_2014?pg=54\#pg54.

[70] P. J. Deuss, K. Barta, J. G. de Vries, Catal. Sci. Technol. 2014, 4, 1174 , https://doi.org/10.1039/C3CY01058A.

[71] W. R. H. Wright, R. Palkovits, ChemSusChem 2012, 5, 1657, https://doi.org/10.1002/cssc.201200111.

[72] S. Dutta, I. K. M. Yu, D. C. W. Tsang, Y. H. Ng, Y. S. Ok, J. Sherwood, J. H. Clark, Chem. Eng. J. 2019, 372, 992, https://doi.org/10.1016/j.cej.2019.04.199.

[73] Z. Xue, Q. Liu, J. Wang, T. Mu, Green Chem. 2018, 20, 4391 https://doi.org/10.1039/C8GC02001A

[74] V. V. Kumar, G. Naresh, M. Sudhakar, J. Tardio, S. K. Bhargava, A. Venugopal, Appl. Catal. A: Gen. 2015, 505, 217, https://doi.org/10.1016/j.apcata.2015.07.031.

[75] V. V. Kumar, G. Naresh, M. Sudhakar, C. Anjaneyulu, S. K. Bhargava, J. Tardio, V.K. Reddy, A. H. Padmasri, A. Venugopal, RSC Adv. 2016, 6, 9872, https://doi.org/10.1039/C5RA24199E.
[76] P. P. Upare, J.-M. Lee, D. W. Hwang, S. B. Halligudi, Y. K. Hwang, J.-S. Chang, J. Ind. Eng. Chem. 2011, 17, 287, https://doi.org/10.1016/j.jiec.2011.02.025.

[77] J. Wang, S. Jaenicke, G.-K. Chuah, RSC Adv. 2014, 4, 13481, https://doi.org/10.1039/C4RA01120A

[78] B. Putrakumar, N. Nagaraju, V. P. Kumar, K. V. R. Chary, Catal. Today 2015, 250, 209, https://doi.org/10.1016/j.cattod.2014.07.014.

[79] W. Bonrath, A. M. C. F. Castelijns, J. G. de Vries, R. P. M. Guit, J. Schütz, N. Sereinig, H. W. L. M. Vaessen, Catal. Lett. 2016, 146, 28.

[80] Q.-S. Kong, X.-L. Li, H.-J. Xu, Y. Fu, Fuel Process. Technol. 2020, 209 106528, https://doi.org/10.1016/j.fuproc.2020.106528.

[81] A. A. Rosatella, S. P. Simeonov, R. F. M. Frade, C. A. M. Afonso, Green Chem. 2011, 13, 754, https://doi.org/10.1039/C0GC00401D.

[82] Y. Román-Leshkov, C. J. Barrett, Z. Y. Liu, J. A. Dumesic, Nature 2007, 447, 982, https://doi.org/10.1038/nature05923.

[83] a) A. S. K. Hashmi, T. M. Frost, J. W. Bats, J. Am. Chem. Soc. 2000 122, 11553, https://doi.org/10.1021/ja005570d; b) B. Martín Matute, D. J. Cárdenas, A. M. Echavarren, Angew. Chem. Int. Ed. 2001, 40, 4754, https://doi.org/10.1002/1521-3773(20011217)40:24<4754::AIDANIE4754>3.0.CO;2-9.

[84] M. Méndez, M. P. Muñoz, C. Nevado, D. J. Cárdenas, A. M. Echavarren, J. Am. Chem. Soc. 2001, 123, 10511, https://doi.org/10.1021/ja0112184.

[85] a) A. Fürstner, Chem. Soc. Rev. 2009, 38, 3208 , https://doi.org/10.1039/B816696J; b) A. Fürstner, Acc. Chem. Res. 2014, 47, 925, https://doi.org/10.1021/ar4001789.

[86] A. S. K. Hashmi, M. C. Blanco, E. Kurpejovic, W. Frey, J. W. Bats, $A d v$ Synth. Catal. 2006, 348, 709, https://doi.org/ 10.1002/adsc.200606012.

[87] N. Huguet, D. Lebœuf, A. M. Echavarren, Chem. Eur. J. 2013, 19, 6581, https://doi.org/10.1002/chem.201300646.

[88] 'Code of Practice - Acetylene', https://www.eiga.eu/publications/eiga-documents/doc-12313-code-of-practice-acetylene/, accessed April 30, 2021.

[89] W. Bonrath, U. Letinois, T. Netscher, WO Patent Appl. No. WO2015110655, 2015.

[90] E. A. Fehnel J. Am. Chem. Soc. 1972, 94, 3961, https://doi.org/10.1021/ja00766a051.

[91] W. Bonrath, U. Letinois, T. Netscher WO Patent Appl. No. WO2015110654, 2015.

[92] A. Zeiler, M. J. Ziegler, M. Rudolph, F. Rominger, A. S. K. Hashmi, Adv. Synth. Catal. 2015, 357, 1507, https://doi.org/10.1002/adsc.201500081.

[93] U. Letinois, T. Netscher, WO Patent Appl. No. WO2016096566, 2016.

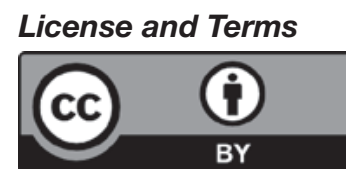

This is an Open Access article under the terms of the Creative Commons Attribution License CC BY 4.0. The material may not be used for commercial purposes.

The license is subject to the CHIMIA terms and conditions: (http:// chimia.ch/component/sppagebuilder/?view=page $\& i d=12$ ).

The definitive version of this article is the electronic one that can be found at https://doi.org/10.2533/chimia.2021.757 